\title{
Vadeli ve Spot Kurlar Arasında Nedensellik ve Fiyat Keşfi: Borsa İstanbul Üzerine Ampirik Bir Analiz
}

Fatih GÜZEL (https://orcid.org/0000-0002-4153-3933), Department of Business Administration, Kurşehir Ahi Evran University, Turkey; e-mail: fatih.guzel@ahievran.edu.tr

\section{Causality and Price Discovery between Spot and Futures Foreign Exchange Rates: An Empirical Analysis on Borsa Istanbul}

\begin{abstract}
USD/TRY foreign exchange rate is the dominant foreign exchange unit in the foreign trade volume of Turkey. This study examines the interaction of the USD/TRY foreign exchange rates formed in the spot and the derivatives markets. The dataset consists of daily frequency data covering January 01, 2014 - December 31, 2018. The interaction between the markets is analysed in terms of price discovery and causality. Hasbrouck (1995) Information Share, Gonzalo and Granger (1995) Component Share, and Putniņš (2013) Information Leadership Share were used as price discovery measures. Price discovery measures agree that futures foreign exchange values have a price discovery function. As a result of the study, a bidirectional causality is determined between the spot and futures foreign exchange rates. Causality from the futures market to the spot market is stronger than the causality from the spot market to the futures markets.

Keywords $\quad$ : Foreign Exchange, Causality, Price Discovery, Borsa Istanbul.

JEL Classification Codes : C01, F31, G14.

Öz

USD/TRY döviz birimi Türkiye dış ticaretine hâkim dövizdir. Bu makale spot ve türev piyasalar arasında USD/TRY döviz biriminin etkileşimini incelemektedir. Veri seti 02.01.2014 31.12.2018 dönemini kapsayan günlük frekanslı verilerden oluşmaktadır. Piyasalar arasındaki etkileşim hem fiyat keşfi hem de nedensellik çerçevesinde analiz edilmiştir. Fiyat keşif ölçütleri olarak Hasbrouck (1995) Bilgi Payı, Gonzalo ve Granger (1995) Bileşen Payı ve Putniņš (2013) Bilgi Liderliği Payı kullanılmıştır. Fiyat keşif ölçütleri vadeli döviz değerlerinin fiyat keşif fonksiyonuna sahip olduğu noktasında uzlaşı içerisindedir. Çalışma sonucunda, spot ve vadeli döviz değerleri arasında çift yönlü nedensellik tespit edilmiştir. Vadeli piyasadan spot piyasaya olan nedensellik, spot piyasadan vadeli piyasalara olan nedensellikten daha güçlüdür.
\end{abstract}

Anahtar Sözcükler $\quad$ : Döviz Kuru, Nedensellik, Fiyat Keşfi, Borsa İstanbul. 
Güzel, F. (2021), "Vadeli ve Spot Kurlar Arasında Nedensellik ve Fiyat Keşfi:

Borsa İstanbul Üzerine Ampirik Bir Analiz”, Sosyoekonomi, 29(48), 427-442.

\section{Giriş}

Vadeli piyasalar, diğer piyasaları tamamlayarak katılımcıların refahını artırma, volatiliteyi etkileme, yeni bilgilerin hızlı yansıtılmasını sağlayarak portföy yönetimini daha hızlı ve düşük maliyetle gerçekleştirme, kısıtlamaların daha az olması nedeniyle bilgilerin işleme dönüşmesini sağlama ve dayanak varlığa ilişkin bilgileri nitelik ve nicelik bakımından artırma ve piyasa mikroyapı unsurlarının eliminasyonu gibi birçok etkiye sahiptir (Damodaran \& Subrahmanyam, 1992: 5). Bununla birlikte, vadeli piyasaların temel fonksiyonları risk yönetimi ve fiyat keşfi olarak özetlenebilir (Kayalıdere vd., 2012: 138).

Risk yönetimi, mevcut risk durumunu tanımlama, alternatifleri değerlendirme ve proaktif kontrol çabalarını kapsamaktadır. Finansal açıdan değerlendirildiğinde risk yönetimi, genel anlamda hedging ve spekülasyon faaliyetlerinden oluşmaktadır. Finansal risklerin yönetimi için farklı boyutlar kazanan risk unsurları ve yatırımcıların talepleri doğrultusunda yeni finansal enstrümanlar geliştirilmektedir. Bu enstrümanlar arasında en önemli olanları türev enstrümanlardır (Chambers, 1998: 1). Finansal risklerden korunma amaçlı türev ürün kullanma nedenleri arasında; finansal piyasalardaki volatilite, vergisel avantajlar, borçlanma kapasitesinin artışı, spot piyasalardaki yetersizlikten kaynaklanan nakit akışı düzensizlikleri ve vade uyuşmazlıklarını önlemek sayılabilir (Prabha vd., 2014: 5; Erdoğan \& Kayacan, 1998: 32).

Vadeli piyasalar, geleceğe ilişkin çeşitli ve dağınık görüşlerin bir beklenti üzerine fikir birliğine varılarak, belirli bir sistematik dâhilinde toplandığı mekanizmalardır. Türev piyasalar aracılığıyla piyasa katılımcıları, her türlü bilgi ve beklentiyi fiyatlara yansıtır. Diğer piyasalara nispeten düşük işlem maliyetleri, kaldıraç etkisi ve yüksek likidite (Chen \& Gau, 2009: 75) nedeniyle varlık fiyatlarına ilişkin bilgi ve beklentiler öncelikle türev ürünler üzerinden fiyatlandırılır (Culp, 2010: 58). Bu nedenle, vadeli piyasa fiyatlarının spot piyasa fiyatlarının gelecekteki değerlerinin tahmin aracı olarak kullanılabilmesi "fiyat keşfi" kapsamında değerlendirilir (Prabha vd., 2014: 40). Fiyat keşfi, bir bilgi akış mekanizmasıdır ve piyasalar arasında öncüllük-gecikme ilişkisini ifade etmektedir. Yeni bilgileri daha hızlı emen ve yansitan piyasalar, fiyat keşfi fonksiyonuna sahiptir (Chen \& Zheng, 2008: 3). Aynı dayanak varlığa ilişkin birden fazla fiyat serisi varsa; dayanak varlığın birden fazla piyasada işlem görmesi veya aynı piyasa bünyesinde dayanak varlığa ilişkin farklı sözleşmelerin bulunması halinde, fiyat keşfinin kapsamı hangi piyasa veya sözleşmenin dayanak varlığın gerçek değerine ilişkin yeni bilgileri daha önce yansıttığıdır (Putniņ̌̌, 2013: 68). Piyasalar arasındaki dinamik ilişkinin fiyat keşfi çerçevesinde incelenmesi, riskten korunma ve arbitraj fırsatları gibi çeşitli nedenlerden ötürü yatırımcılar, düzenleyici kesim, aracı kuruluşlar ve diğer piyasa aktörleri için faydalıdır. Ek olarak, menkul kıymet piyasalarının en önemli hedefi gerçeğe uygun değeri tespit edip, piyasa etkinliğini optimal düzeyde sağlamak olduğundan, fiyat keşfinin yerini ve niteliğini belirlemek elzemdir.

Genel anlamda dalgalı kur sisteminin uygulandığı Türkiye gibi gelişmekte olan ülkeler için döviz kuru riski oldukça önemlidir. Döviz kuru riskinden korunmak ve bu riski bir yatırım firsatı olarak değerlendirebilmek için türev piyasalar önemli bir unsurdur. Ancak, 
türev enstrümanların risk yönetimi amacıyla kullanılabilmesi için piyasalar arasındaki kısa ve uzun dönemli döviz kuru ilişkilerinin tespit edilmesi gerekmektedir. $\mathrm{Bu}$ çalışmanın amacı, Türkiye'nin ekonomik faaliyetleri ve dış ticaretinde en büyük paya sahip döviz birimi olan Amerikan doları ${ }^{1}$ değerinin spot ve türev piyasalar arasındaki etkileşiminin incelenmesidir. Analiz ve değerlendirmeler fiyat keşfi ve nedensellik ilişkileri perspektifinde yapılacaktır. Böylece, Türkiye'de Amerikan doları için hangi piyasanın yeni bilgileri fiyatlara yansıtma konusunda öncü, hangisinin ise takip eden konumunda olduğu tespit edilmiş olacaktır. Bu sonuçlar gerek riskten korunma gerekse yeni yatırım firsatları açısından oldukça önem arz etmektedir. Ayrıca, ulusal literatür kapsamında döviz piyasaları arasında nedensellik ilişkisi incelenmesine rağmen, yapılan literatür taraması sonucunda piyasaların bilgi işleme hızı ve bilgisel referans olarak konumu, başka bir ifade ile piyasaların fiyat keşfi özellikleri ve ilgili oranların henüz bir araştırmaya konu olmadığ tespit edilmiştir. Uluslararası literatürde döviz kuru için fiyat keşfi çerçevesinde yapılan çalışmalar (Tse vd., 2006; Cabrera vd., 2009; Chen \& Gau, 2010; Guru, 2010; De Boyrie vd., 2012; Sehgal vd., 2015; Sakthivel vd., 2017; Kumar, 2018) bulunmakla birlikte, Türkiye için herhangi bir incelemeye rastlanmamaktadır. Bu çalışma ile Türkiye için Amerikan doları spot ve vadeli döviz piyasaları arasındaki fiyat keşif -öncüllük/gecikme- süreci fiyat keşif oranları vasıtasıyla analiz edilerek hem ulusal literatüre katkı sağlamak hem de döviz piyasaları üzerine fiyat keşfi çerçevesinde alternatif bir perspektif kazandırmak hedeflenmektedir.

Küresel kriz sonrasında, özellikle gelişmiş ülkelerde krizden çıkış reçetesi, para politikalarının yanı sıra etkin maliye politikalarının da uygulanması olarak sunulmuştur. $\mathrm{Bu}$ bağlamda gelişmiş ülkelerin uyguladığı genişletici maliye ve para politikaları küresel likidite düzeyini artırmıştır. Parasal genişleme ile gelişmiş dünya ekonomileri enflasyon seviyelerini artırmaya gayret ederken, gelişmekte olan ülkelerde enflasyonun yükselmesi endişeleri yaşanmıştır. Özellikle Japonya gibi talep yetersizliği olan ülkeler deflasyon riski ile karşı karşıya kalmıştır. 2008 küresel kriz öncesinde büyük oranda enflasyon hedeflemesi rejimine bağlı kalan gelişmiş ülkelerin Merkez Bankaları, kriz sonrasında finansal istikrarın sağlanması ve korunmasını da hedeflerine eklemiştir. Bu gelişmelere benzer şekilde, TCMB küresel kriz sonrasında fiyat istikrarının yanı sıra kısa vadeli sermaye akımlarındaki oynaklığın ve risk iştahının dengelenmesi amacıyla finansal istikrarı sağlayacak politika arayışlarına girmiştir. 2013 yılında ABD Merkez Bankası FED’in kademeli faiz artışına gideceği yönündeki kararı, küresel piyasalarda parasal genişlemenin azalacağına ilişkin beklentileri artırmıştır. Böylelikle 2013 yılına kadar Türkiye ekonomisinde güçlü sermaye akımlarının etkisiyle döviz kuru yatay bir seyir izlerken; 2013 yılının son çeyreğinde parasal genişlemenin kademeli olarak azaltılacağına ilişkin görünüm Türk lirasının dolar karşısında değer kaybetmesine neden olmuştur. TCMB, ulaşılan enflasyon düzeyinin, hedeflenin üzerinde gerçekleşmesi nedeniyle, 2014-2018 döneminde piyasa aktörlerinin beklediği düzeyde faiz yükselişini gerçekleştirmemiştir. Beklenen faiz artışının gerçekleşmemesi ve

2013-2019 Türkiye diş ticaret istatistikleri incelendiğinde; ihracatın \%45'i, ithalatın \%61 ve toplam diş ticaretin \%54'ünün Amerikan dolarl ile gerçekleştirildiği görülmektedir (Türkiye İstatistik Kurumu, 2020). 
öngörülemeyen para politikaları döviz kurunun hızla yükselmesine neden olmuştur. 2014 yılının başında 2 lira olan USD/TL paritesi, çeşitli ulusal ve küresel faktörlerin de etkisiyle müteakip yıllarda yüksek oynak bir yapı sergilemiş ve 2018 yılında 7 liraya yaklaşmıştır. Özetle, 2014-2018 dönemi USD/TL paritesi açısından oldukça hareketli bir dönemdir. Finansal değerdeki değişim/hareket, veri veya gürültü kaynaklı olabilmekte, genel anlamda bilgi akışından kaynaklanmaktadır. Bu koşullarda, bilginin hangi ortamda/piyasada daha etkin işlendiği, değerin daha hızlı ve doğru belirlendiği önem arz etmektedir. Sonuç olarak bu çalışma, piyasaların veri işleme performansını döviz kuru değişimlerinin yoğun olarak yaşandığı 2014-2018 dönemi için karşılaştırmaktadır. Analiz sonuçları vadeli piyasaların döviz kurunu belirlemede spot piyasalara göre daha etkin olduğunu göstermektedir.

Çalışmanın müteakip kısımları sırasıyla şöyle organize edilmiştir. İkinci bölüm mevcut literatürün kısa özetidir. Üçüncü bölüm veri setine ilişkin bilgileri içermektedir. Dördüncü bölüm metodolojiyi açıklamaktadır. Beşinci bölüm elde edilen bulguları kapsamaktadır. Son bölümde ise, bulguların değerlendirilmesi yapılmaktadır.

\section{Literatür}

Döviz türev enstrümanları üzerine çok sayıda çalışma bulunmaktadır. Ayrıca döviz piyasalarına ilişkin çalışma alanı da oldukça geniştir. İncelenen alana ilişkin literatür özeti Tablo 1'de yer almaktadır.

Tablo: 1

Spot ve Vadeli Döviz Kuru İlişkisine Yönelik Ampirik Literatürün Özeti

\begin{tabular}{|c|c|c|c|c|}
\hline Yazar (YII) & Borsa & Para Birimi & Dönem & Bulgular \\
\hline $\begin{array}{l}\text { Tse vd. } \\
(2006)\end{array}$ & CME & EUR/USD, JPY/USD & $\begin{array}{l}03.05 .2004 \\
30.06 .2004\end{array}$ & $\begin{array}{l}\text { Fiyat Keşfi: Futures } \rightarrow \text { Spot (EUR), } \\
\text { Spot } \rightarrow \text { Futures (JPY) }\end{array}$ \\
\hline $\begin{array}{l}\text { Çevik ve Pekkaya } \\
(2007)\end{array}$ & TurkDEX & USD/TRY, EUR/TRY & $\begin{array}{l}04.02 .2005 \\
28.09 .2006 \\
\end{array}$ & Nedensellik: Futures $\rightarrow$ Spot \\
\hline $\begin{array}{l}\text { Cabrera vd. } \\
(2009)\end{array}$ & CME & EUR/USD, JPY/USD & $\begin{array}{l}04.04 .2005 \\
29.06 .2005 \\
\end{array}$ & Fiyat Keşfi: Spot $\rightarrow$ Futures $\rightarrow$ E-mini Futures \\
\hline $\begin{array}{l}\text { Ozen vd. } \\
(2009)\end{array}$ & TurkDEX & USD/TRY & $\begin{array}{l}02.2005 \\
02.2009 \\
\end{array}$ & $\begin{array}{l}\text { Nedensellik: Futures } \rightarrow \text { Spot (Kısa Dönem), } \\
\text { Spot } \rightarrow \text { Futures (Uzun Dönem) }\end{array}$ \\
\hline $\begin{array}{l}\text { Chen ve Gau } \\
(2010)\end{array}$ & CME & JPY/USD, EUR/USD & $\begin{array}{l}01.01 .2004 \\
31.12 .2005\end{array}$ & Fiyat Keşfi: Spot $\rightarrow$ Futures (JPY, EUR) \\
\hline $\begin{array}{l}\text { Demireli vd. } \\
(2010)\end{array}$ & TurkDEX & USD/TRY, EUR/TRY & $\begin{array}{l}04.02 .2005 \\
25.12 .2009 \\
\end{array}$ & Nedensellik: Futures $\rightarrow$ Spot \\
\hline Guru (2010) & NSE & USD/INR & $\begin{array}{l}29.08 .2008 \\
28.08 .2009\end{array}$ & $\begin{array}{l}\text { Fiyat Keşfi: Futures } \rightarrow \text { Spot } \\
\text { Nedensellik: Spot } \leftrightarrow \text { Futures }\end{array}$ \\
\hline $\begin{array}{l}\text { De Boyrie vd. } \\
\text { (2012) }\end{array}$ & CME & RUB/USD, BRL/USD, ZAR/USD & $\begin{array}{l}03.01 .2005 \\
30.03 .2011\end{array}$ & $\begin{array}{l}\text { Fiyat Keşfi: Futures } \rightarrow \text { Spot (BRL), } \\
\text { Spot } \rightarrow \text { Futures (RUB, ZAR) }\end{array}$ \\
\hline $\begin{array}{l}\text { Unlu ve Ersoy } \\
\text { (2012) }\end{array}$ & TurkDEX & USD/TRY & $\begin{array}{l}01.2007 \\
12.2011\end{array}$ & Nedensellik: Spot $\leftrightarrow$ Futures \\
\hline $\begin{array}{l}\text { Sehgal vd. } \\
(2015)\end{array}$ & MCX-SX, NSE & $\begin{array}{l}\text { USD/INR, GBP/INR, EUR/INR, } \\
\text { JPY/INR }\end{array}$ & $\begin{array}{l}01.02 .2010 \\
29.02 .2012 \\
\end{array}$ & Fiyat Keşfi: Futures $\rightarrow$ Spot \\
\hline $\begin{array}{l}\text { Sakthivel vd. } \\
\text { (2017) }\end{array}$ & NSE & $\begin{array}{l}\text { USD/INR, JPY/INR, GBP/INR, } \\
\text { EUR/INR }\end{array}$ & $\begin{array}{l}01.03 .2010 \\
20.01 .2015\end{array}$ & $\begin{array}{l}\text { Nedensellik: Spot } \leftrightarrow \text { Futures (USD), } \\
\text { Spot } \rightarrow \text { Futures (JPY, GBP, EUR) } \\
\text { Fiyat Keşfi: Spot } \rightarrow \text { Futures }\end{array}$ \\
\hline $\begin{array}{l}\text { Kumar } \\
(2018)\end{array}$ & NSE & USD/BRL, USD/ZAR, USD/INR & $\begin{array}{l}02.09 .2008 \\
27.04 .2018 \\
\end{array}$ & $\begin{array}{l}\text { Fiyat Keşfi: Futures } \rightarrow \text { Spot (BRL), } \\
\text { Spot } \rightarrow \text { Futures (INR, ZAR) }\end{array}$ \\
\hline
\end{tabular}

Tablo 1 incelendiğinde gerek fiyat keşfi ve gerekse nedensellik ilişkisi açısından, incelenen çalışmaların sonuçlarında görüş birliği bulunmadığı görülmektedir. Bu durum ise, 
incelenen döviz cinsi ve piyasaya göre sonuçların farklılaştığ 1 anlamına gelmektedir. Fiyat keşfi açısından değerlendirildiğinde; Tse vd. (2006) (JPY), Cabrera vd. (2009), Chen ve Gau (2010), De Boyrie vd. (2012) (RUB, ZAR), Sakthivel vd. (2017), Kumar (2018) (INR, ZAR) spot piyasanın türev piyasalara öncüllük ettiğini; Tse vd. (2006) (EUR), Guru (2010), De Boyrie vd. (2012) (BRL), Sehgal vd. (2015), Kumar (2018) (BRL) türev piyasaların spot piyasalara öncüllük ettiğini raporlamışlardır. İncelenen yabancı literatür çalışmalarının nedensellik ilişkisi sonuçlarına göre; değişkenler arasında çift yönlü bir nedensellik ilişkisi bulunmaktadır (Guru, 2010; Sakthivel vd., 2017). Türkiye finansal piyasalarını konu alan çalışmalar için ise, farklı bir durum söz konusudur. Çevik ve Pekkaya (2007), Ozen vd. (2009) (k1sa dönem) ve Demireli vd. (2010) nedensellik yönünün türev piyasalardan spot piyasalara doğru olduğunu belirtmişlerdir. Ozen vd. (2009) (uzun dönem) nedensellik yönünün spot piyasalardan türev piyasalara doğru olduğunu, Unlu ve Ersoy (2012) ise, çift yönlü bir nedensellik bulgusunu raporlamıştır. Türkiye finansal piyasalarında döviz kurları için piyasaların fiyat keşfi henüz bir çalışmaya konu olmamıştır. Mevcut çalışma ile literatürdeki bu boşluğun doldurulması amaçlanmaktadır.

\section{Veri Seti}

Çalışmada USD/TRY döviz kuru için spot ve türev piyasaları temsil eden iki değişken oluşturulmuştur. Spot piyasa verisi olarak Türkiye Cumhuriyet Merkez Bankası (TCMB) döviz kuru değerleri kullanılmıştır. Türev piyasa verisi olarak ise vadeli işlem sözleşme değerleri kullanılmıştır. Borsa İstanbul (BİST) Vadeli İşlem ve Opsiyon Piyasası (VİOP) bünyesinde aynı anda içinde bulunulan ay, takip eden ay, sonraki üç döngü ayı (Vade Döngü Ayları: Şubat, Nisan, Haziran, Ağustos, Ekim, Aralık) ve aynı yılın Aralık ayı olmak üzere toplam altı vade ayına ait sözleşmeler işlem görmektedir. Altı vade ayını tamamlamak için gerektiğinde bir sonraki takvim yılının Aralık vadeli işlem sözleşmeleri de ayrıca işleme açılmaktadır. Başka bir ifade ile USD/TRY döviz kuru dayanak varlığını referans alan altı sözleşme işlem görmektedir (Borsa İstanbul, 2020). Çalışmada, en yakın vade tarihine sahip sözleşmelerin en yüksek işlem hacmine sahip olduğu tespit edilmiştir ve literatürle uyumlu olarak bu verilerin birbirine bağlanması ile devamlı bir veri seti oluşturulmuştur. Sonuç olarak, vadeli işlem sözleşmeleri için en yakın vade tarihine sahip sözleşmelerin uzlaşma fiyatları gözlem birimi olarak kullanılmıştır. Tablo 2'de değişkenlere ilişkin betimleyici bilgiler yer almaktadir.

Tablo: 2

\section{Değişkenlere İlişkin Bilgiler}

\begin{tabular}{|l|l|l|l|l|}
\hline Değişken & Dönüşüm Türü & Sembol & Frekans & Kaynak \\
\hline Spot USD/TRY & Logaritmik & lspot & Günlük & TCMB EVDS \\
\hline Futures USD/TRY & Logaritmik & lfutures & Günlük & BİST DataStore \\
\hline
\end{tabular}

Veri seti 02.01.2014 - 31.12.2018 dönemini kapsamaktadır. Veri frekansı ise günlük düzeydedir. Serilerde olası üstel büyüme ve aykırı gözlemlerin etkilerini minimize etmek amacıyla verinin doğal logaritması alınarak analizler gerçekleştirilmiştir. 
Güzel, F. (2021), "Vadeli ve Spot Kurlar Arasında Nedensellik ve Fiyat Keşfi:

Borsa İstanbul Üzerine Ampirik Bir Analiz”, Sosyoekonomi, 29(48), 427-442.

\section{Metodoloji}

Çalışmada, öncelikle verilerin durağanlığı araştırılmıştır. Durağanlığın tespiti için Artırılmış Dickey Fuller (ADF) (1981), Phillips Perron (PP) (1988) ve KwiatkowskiPhillips-Schmidt-Shin (KPSS) (1992) birim kök testleri uygulanmıştır. Entegrasyon derecelerinin belirlenmesinin akabinde; değişkenler arasındaki eşbütünleşme ilişkisinin tespiti için Johansen Eşbütünleşme testi (1991, 1995), ilişkinin kısa dönem dinamiklerinin tespiti için vektör hata düzeltme modeli (VECM) kullanılmıştır. Değişkenler arasındaki öncül - ardıl ilişkisi ise fiyat keşif ölçütleri aracılığıyla hesaplanmıştır. Son olarak değişkenlere ilişkin nedensellik ilişkisi analiz edilmiştir.

Zaman serilerinin analizinde sahte regresyon sorunundan kaçınmak için öncelikle durağanlığın testi gerekmektedir. Sahte regresyon, değişkenler arasındaki yüksek korelasyonun gerçek ilişkiyi yansıtmaması ve yanıltıcı sonuçlar doğurmasına neden olmaktadır (Granger \& Newbold, 1974: 111). Durağanlığın testinde çoğunlukla tercih edilen analiz yöntemi, sonuçların diğer yöntemlere kıyasla daha net yorumlanmasına imkân sağlayan birim kök testleridir (Sakarya \& Akkuş, 2018: 358). Birim kök testleri içinde ADF, PP ve KPSS testleri sıkça tercih edilen testlerdir. Serilerin durağanlığ 1 ADF ve PP testlerinde aynı şekilde belirlenmektedir (Gujarati, 2004: 818). Boş hipotez birim kök varlığını, alternatif hipotez ise durağanlığı ifade etmektedir. Durağanlığın kabulü için elde edilen istatistiklerin mutlak değerinin MacKinnon kritik değerlerinin mutlak değerinden büyük olması gerekmektedir. KPSS testinde ADF ve PP testlerine göre hipotezleri ters kurulmuştur. Boş hipotez durağanlık ve alternatif hipotez birim kök varlığını işaret etmektedir. KPSS testinde durağanlık için elde edilen istatistiklerin mutlak değerinin KPSS kritik değerlerinin mutlak değerinden küçük olması gerekmektedir.

Seriler arasında ortak düzeyde aynı stokastik trende sahip olma durumu olarak ifade edilen eşbütünleşme sıklıkla gözlenmektedir (Stock \& Watson, 2015: 702). Eşbütünleşme, durağan olmayan değişkenler arasındaki uzun dönemli birlikte hareketi gösteren denge ilişkisini ortaya koymaktadır. Durağan olmayan seriler arasında eşbütünleşme ilişkisinin bulunmaması, tahmin edilecek regresyon modelinde sahte regresyon sonucunu doğuracaktır (Sevüktekin \& Çınar, 2017: 560). Çalışmada Johansen eşbütünleşme analizi metodolojisi takip edilmiştir. Johansen yöntemi durağan olmayan (I(1)) zaman serileri ile oluşturulan Vertör Otoregresif (VAR) modeline dayanmaktadır. Johansen yönteminin testinde, Johansen $(1988,1995)$ ile Johansen ve Juselius (1990) tarafindan geliştirilen Vektör Hata Düzeltme Modeli (VECM) kullanılır.

Eşbütünleşme analizleri uzun dönemli ilişkinin tespiti, hata düzeltme modelleri (ECM) ise, kısa dönem iliş̧ki dinamiklerinin tespiti için yapılmaktadır (Tarı, 2011: 435). Hata düzeltme modeli, bağımlı değişkendeki değişmenin, bağımlı ve bağımsız değişkenlerin gecikmeli değerleri ile uzun dönemli ilişkinin hata terimi arasında kurulan regresyon yardımıyla çözülmektedir (Akıncı \& Tuncer, 2016: 50). Hata düzeltme modeli denkleminden elde edilen hata düzeltme katsayısı ile değişkenler arasındaki kısa dönemli ilişki yorumlanmaktadır. Hata düzeltme katsayısı $(\alpha)$ istatistiksel olarak anlamlı ise, kısa 
dönemli dengeden sapma olduğu söylenebilir. $\alpha$ 'nın 0 ile -1 arasında yer alması beklenmekle birlikte değişken sayısı ve veri karakteristiği gibi unsurlar göz önüne alındığında bu değerin -2’lere kadar genişleyebileceği çeşitli çalışmalarda belirtilmiştir (Enders, 2014: 353-360; Narayan \& Smyth, 2006: 339). $\alpha$ istatistiği negatif değer alırsa sapma uzun dönem değerine yaklaşmakta, pozitif değer alırsa dengeden uzaklaşma yorumu yapılabilir (Tarı, 2011: 435). Sonuç olarak, sapmalar kısa dönemde hata düzeltme vektörü nispetinde düzeltilmektedir (Bilgin \& Şahbaz, 2009: 186).

Fiyat keşif oranları, aynı finansal varlığı değerleyen piyasa veya finansal enstrümanların yeni bilgilere uyum hızlarının tespiti ve kıyaslanması adına kullanılmaktadır. Hasbrouck (1995) Bilgi Payı (Information Share-IS), Gonzalo ve Granger (1995) Bileşen Payı (Compenent Share-CS) ve Putniņš (2013) Bilgi Liderliği Payı (Information Leadership Share-ILS) sıklıkla kullanılan fiyat keşif oranlarıdır. Fiyat keşif oranları VECM parametrelerinin kullanımı ve yorumlanması aracılığıyla hesaplanmaktadır.

CS, Gonzalo ve Granger'in (1995) eşbütünleşme ekonometrisi üzerine çalışmasına dayanır ve ilk olarak Booth vd. (1999), Chu vd. (1999) ve Harris vd. (2002) tarafindan fiyat keşfi alanına uygulanmıştır. Gonzalo ve Granger (1995), eşbütünleşik fiyat serilerini hata düzeltme katsayılarını kullanarak kalıcı bir bileşene ve geçici bir bileşene ayrıştırma yöntemini önermektedir. Fiyat keşfi bağlamında, kalıcı bileşen ortak etkin fiyat olarak yorumlanır ve geçici bileşen piyasa mikroyapısı gibi çeşitli unsurlardan kaynaklanan sapmaları yansıtır. Gonzalo ve Granger (1995), kalıcı bileşenin eşbütünleşme sistemindeki tüm değişkenlerin (fiyat serileri) doğrusal bir kombinasyonu olduğunu göstermektedir (Putniņš, 2013: 70). CS, değişkenlerin ortak etkin fiyata katkısını veya doğrusal kombinasyondaki ağırlıklarını VECM hata düzeltme katsayısı $(\alpha)$ aracılığıyla ölçmektedir. İki piyasadan birincisi fiyat keşif sürecinde baskın olduğunda $\alpha_{1}, \alpha_{2}$ ye göre daha küçük bir mutlak değere sahip olacak, piyasa dengesizliklerinden daha az etkilenecek ve $\alpha_{1}$ öncül konumda bulunacaktır (Inani, 2018: 136). Kısaca, CS'ye göre bir fiyat serisinin fiyat keşfine katkısı ortak etkin fiyatı oluşturan doğrusal fiyat kombinasyonundaki normalize edilmiş ağırlığıdır.

Aynı varlığı değerleyen farklı enstrümanın veya piyasaların fiyatları, mikroyapı vb. faktörler nedeniyle kısa dönemde birbirinden sapma gösterse bile uzun vadede dengeye gelecek ve ortak etkin fiyat çizgisinde buluşacaktır. Hasbrouck (1995), ortak etkin fiyat değişimlerini varyansına ayrıştırır ve bir fiyat serisi veya piyasa tarafından açıklanan varyans oranının ilgili piyasanın fiyat keşfine katkısı (bilgi payı-IS) olarak nitelendirir. IS, her bir piyasa veya enstrümanın ortak etkin fiyat varyansına olan katkısını ölçmektedir. En yüksek IS değerine sahip birim yeni bilgilere önce tepki vererek diğer birimleri yönlendirir. Bir birimdeki değişimler diğer birim veya birimlerdeki değişimleri tetikliyorsa, bu birim bilgi olarak baskındır (Cabrera, 2009: 144).

Yan ve Zivot (2010), varlık fiyatları için oldukça genel bir yapısal eşbütünleşme modeli belirlemiş ve IS ve CS'nin bu model kapsamında neyi ölçtüğünü analitik olarak göstermiştir. Yan ve Zivot (2010) modelinde fiyat serileri geçici ve kalıcı olmak üzere iki 
şok kaynağı tarafından belirlenmektedir. Kalıcı şoklar etkin fiyattaki yenilikleri temsil eder ve bir birim kalıcı şok uzun vadede fiyatlarda bir birim artışa neden olur. Geçici şok, mikroyapı vb. unsurlardan kaynaklanan gürültüyü temsil eder ve bir birim geçici şok uzun vadede fiyatlar üzerinde sıfır etkiye sahiptir. IS ve CS'nin, geçici şoklara dinamik tepkiye bağımlı olmaları nedeniyle bazı durumlarda fiyat keşfi hakkında yanıltıcı bilgiler verebilmektedir. Yan ve Zivot (2010) IS ve CS oranını birleştirerek her bir ölçünün farklı gürültü seviyelerine olan duyarlılığını elimine eden yeni bir ölçü geliştirmiştir. Böylece, gürültünün etkisine maruz kalmayan ve sadece bilgi işleme hızını referans alan bir ölçü tasarlanmıştır. Ancak geliştirilen ölçü bir oran olarak tasarlanmamıştır. Bu ölçü daha kolay yorumlanması ve diğer fiyat keşif oranlarıyla kıyaslanabilmesi adına Putniņš (2013) tarafından Bilgi Liderliği Payı (Information Leadership Share -ILS) adı altında revize edilmiştir.

Hata düzeltme katsayıları ve hata terimlerinin varyans - kovaryansları aracılığıyla fiyat keşif oranları şu şekilde hesaplanmaktadır (Baillie, 2002; Yan \& Zivot, 2010; Putniņš, 2013):

CS, hata düzeltme katsayıları vektörüne normalize edilmiş ortogonalden elde edilir $\alpha_{\perp}=\left(\gamma_{1}, \gamma_{2}\right)^{\prime}$, böylece:

$$
C S_{1}=\gamma_{1}=\frac{\alpha_{2}}{\alpha_{2}-\alpha_{1}}, C S_{2}=\gamma_{2}=\frac{\alpha_{1}}{\alpha_{1}-\alpha_{2}}
$$

Burada; $\alpha_{1}$ ilk serinin hata düzeltme katsayıs1, $\alpha_{2}$ ikinci serinin hata düzeltme katsayısıdır. $C S_{1}$ ve $C S_{2}$ sırayla, ilk ve ikinci seriye ilişkin bileşen payı oranlarıdır. IS ise şöyle hesaplanmaktadır:

$$
I S_{1}=\frac{\gamma_{1}^{2} \sigma_{1}^{2}}{\gamma_{1}^{2} \sigma_{1}^{2}+\gamma_{2}^{2} \sigma_{2}^{2}}, I S_{2}=\frac{\gamma_{2}^{2} \sigma_{2}^{2}}{\gamma_{1}^{2} \sigma_{1}^{2}+\gamma_{2}^{2} \sigma_{2}^{2}}
$$

$\sigma_{1}^{2}$ ve $\sigma_{2}^{2}$ sırasıyla ilk ve ikinci serinin varyanslarıdır. Bu denklem hata terimleri arasında korelasyon bulunmaması halinde geçerlidir. Böyle bir durumda IS ve CS benzer nitelikte sonuçlar üretecektir. Varyans kovaryans matrisinin $(\Omega)$ diagonal olması durumunda Hasbrouck (1995), korelasyonu elimine etmek için Cholesky ayrıştırmasını $\left(\Omega=M M^{\prime}\right)$ kullanmıştır. VECM hata terimlerinin kovaryans matrisi,

$$
\Omega=\left(\begin{array}{cc}
\sigma_{1}^{2} & \rho \sigma_{1} \sigma_{2} \\
\rho \sigma_{1} \sigma_{2} & \sigma_{2}^{2}
\end{array}\right)
$$

ve onun Cholesky ayrıştırması,

$$
M=\left(\begin{array}{cc}
m_{11} & 0 \\
m_{12} & m_{22}
\end{array}\right)=\left(\begin{array}{cc}
\sigma_{1} & 0 \\
\rho \sigma_{2} & \sigma_{2}\left(1-\rho^{2}\right)^{1 / 2}
\end{array}\right)
$$

Burada; $\rho$ korelasyonu ifade etmektedir. Nihai olarak IS ise, 


$$
I S_{1}=\frac{\left(\gamma_{1} m_{11}+\gamma_{2} m_{12}\right)^{2}}{\left(\gamma_{1} m_{11}+\gamma_{2} m_{12}\right)^{2}+\left(\gamma_{2} m_{22}\right)^{2}}, I S_{2}=\frac{\left(\gamma_{2} m_{22}\right)^{2}}{\left(\gamma_{1} m_{11}+\gamma_{2} m_{12}\right)^{2}+\left(\gamma_{2} m_{22}\right)^{2}}
$$

$\Omega$ 'nın diagonal olmaması durumunda IS tam olarak tanımlanamaz ve sonuçlar değişkenlerin Cholesky ayrıştırması sıralamasından etkilenmektedir (So ve Tse: 2004, 897). Sonuç olarak, IS değeri değişkenlerin VECM denklemindeki sıralamasından etkilenmektedir. Literatürde (Baillie vd. (2002), Booth vd. (2002), Cao vd. (2009), Chen and Gau (2010), Korczak ve Phylaktis (2010), Putniņš, (2013), vd.) her bir sıralamaya ilişkin değerlerin hesaplanıp basit ortalamasının alınması yolu tercih edilmektedir.

ILS oranı ise şöyle hesaplanmaktadır:

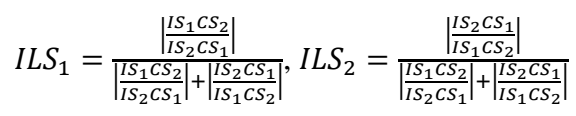

Fiyat keşif ölçütleri birlikte kullanılarak genel bir kanıya varmaya çalışılır. Birbirinin ikamesi olmaktan ziyade birbirinin tamamlayıcı olarak kabul edilmelidir (De Jong, 2002: 327).

Nedensellik testleri yardımıyla değişkenler arasındaki neden-sonuç ilişkisine yönelik analizler yapılmaktadır. Eğer $X_{t}$ değişkeni $Y_{t}$ değişkenin (Granger) nedeniyse, $X_{t}{ }^{\prime}$ teki değişmeler $Y_{t}{ }^{\prime}$ deki değişmelerden daha önce gelmelidir. Dolayısıyla, $Y_{t}{ }^{\prime}$ nin (kendi geçmiş değerleri de dâhil) başka değişkenlere göre regresyonuna $\mathrm{X}_{\mathrm{t}}{ }^{\prime}$ in geçmiş veya gecikmeli değişkenleri de eklendiğinde Yt'nin kestirimi anlamlı bir şekilde iyileşiyorsa, bu durumda $X_{\mathrm{t}}, \mathrm{Y}_{\mathrm{t}}$ 'nin Granger anlamda nedenidir biçiminde ifade edilebilir (Gujarati 2004, 696). Değişkenlerin birim kök içermesi durumunda Granger (1969) nedensellik testi geçersiz olacaktır. Serilerin düzeyde durağan olmaması durumunda değişkenlerin eşbütünleşme ilişkisine bakılması gerekmektedir (Engle \& Granger, 1987: 258-260). Değişkenler arasında eşbütünleşmenin varlığı durumunda standart nedensellik analizinden ziyade, nedenselliğin hata düzeltme modeli çerçevesinde yapılması gerektiği Engle ve Granger (1987) tarafından vurgulanmıştır. Ayrıca, Engle ve Granger (1987) eşbütünleşme ilişkisinin mevcut olması durumunda, en az bir adet uzun dönemli nedensellik ilişkisinin ortaya çıkacağını belirtmiştir. Sonuç olarak, birim kök içeren serilerde eşbütünleşme ilişkisi varlığı durumunda bu ilişkiden sapmalar, kısa ve uzun dönem dengesizliklerinin giderilmesi ve sebep-sonuç ilişkisinin açıklanması için değiş̧enlere yönelik nedensellik analizi hata düzeltme modeli çerçevesinde kurulmalıdır (Demirci, 2017: 54).

\section{Ampirik Bulgular}

Veri seti 02.01.2014 - 31.12.2018 dönemini kapsamakta ve her bir değişken için 1255 gözlem birimi bulunmaktadır. Serilerde olası üstel büyüme ve aykırı gözlemlerin etkilerini minimize etmek amacıyla verinin doğal logaritması alınarak analizler gerçekleştirilmiştir. Analiz sürecinde ilk aşama olarak birim kök testleri yapılmıştır. Farklı karakteristik özelliklere odaklanmaları nedeniyle ADF, PP ve KPSS birim kök testlerine yer verilmiştir. Aşağıda birim kök testleri sonuçlarına yer almaktadır. 
Tablo: 3

Birim Kök Testi Sonuçları

\begin{tabular}{|c|c|c|c|c|}
\hline & & \multicolumn{2}{|c|}{ Trendli ve Kesenli } & \multirow[b]{2}{*}{ Entegresyon Derecesi } \\
\hline Test & Değişken & Düzey & Birinci Fark & \\
\hline \multirow{2}{*}{$\mathrm{ADF}$} & lspot & -2.116 & $-23.150 * * *$ & $\mathrm{I}(1)$ \\
\hline & lfutures & $-3.143^{*}$ & $-22.313 * * *$ & $\mathrm{I}(1)$ \\
\hline \multirow{2}{*}{ PP } & lspot & -2.302 & $-29.711 * * *$ & $\mathrm{I}(1)$ \\
\hline & lfutures & -2.861 & $-30.989 * * *$ & $\mathrm{I}(1)$ \\
\hline \multirow{2}{*}{ KPSS } & lspot & $0.279 * * *$ & 0.040 & $\mathrm{I}(1)$ \\
\hline & lfutures & $0.301 * * *$ & 0.028 & $\mathrm{I}(1)$ \\
\hline \multicolumn{5}{|c|}{ 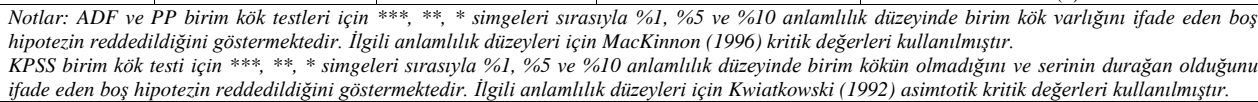 } \\
\hline
\end{tabular}

Her üç birim kök testi spot piyasa fiyatının logaritmik değeri (lspot) için birinci dereceden entegrasyonu raporlamaktadır. Aynı bulgular, $\% 5$ anlamlılık düzeyinde, vadeli piyasayı temsil eden futures sözleşme fiyatının logaritmik değeri (lfutures) için de geçerlidir. PP birim kök testi ADF testi sonuçlarını kontrol amacıyla, KPSS testi ise boş ve alternatif hipotez ayrım gücü zayıflıklarını gidermek amacıyla uygulanmıştır. Sonuç olarak her bir serinin birinci dereceden entegre veya I(1) olduğuna karar verilmiştir.

Değişkenler arasındaki ilişkinin tespitinde uygun gecikme uzunluğu kurulan VAR modeli ile tespit edilmiş; değişkenlerin uzlaşı içinde olduğu ve otokorelasyon probleminin bulunmadığı gecikme uzunluğunun dört olduğu tespit edilmiştir. İlgili gecikme uzunluğuna bağlı olarak müteakip testler gerçekleştirilmiştir. Öncelikle değişkenler arasındaki eşbütünleşme ilişkisine yönelik Johansen eşbütünleşme testi uygulanmıştır. Eşbütünleşme testine ilişkin bulgular Tablo 4'te yer almaktadır.

Tablo: 4

Johansen Eşbütünleşme Testi Sonuçları

\begin{tabular}{|c|c|c|c|c|c|}
\hline Değişken & Testler & Boş Hipotez & Alternatif Hipotez & Test İstatistiği & Kritik Değerler \\
\hline \multirow{2}{*}{ lspot } & \multirow{2}{*}{$\lambda_{i z}$} & $r=0$ & $r>0$ & $30.826^{* *}$ & 15.495 \\
\hline & & $r \leq 1$ & $r>1$ & 0.007 & 3.841 \\
\hline \multirow{2}{*}{ Ifutures } & \multirow{2}{*}{$\lambda_{\max }$} & $r=0$ & $r>0$ & $30.819^{* * *}$ & 14.265 \\
\hline & & $r \leq 1$ & $r>1$ & 0.007 & 3.841 \\
\hline
\end{tabular}

Johansen eşbütünleşme testi sonuçlarına göre değişkenler arasında uzun dönemli bir ilişki bulunmaktadır. Bu durum değişkenlerin uzun dönemde birlikte hareket ettikleri ve etkileşim içinde bulunduklarına işaret etmektedir. Değişkenler arasındaki uzun dönemli ilişkiden sapmaların niteliği ve ilişkinin kısa dönem dinamikleri VECM modeli yardımıyla incelenmektedir. VECM fiyat keşfi ölçütlerinin hesaplanmasında bir referans noktasıdır. $\mathrm{Bu}$ noktadan değerlendirildiğinde katsayı ve testin anlamlılığ önem arz etmektedir. Aşağıdaki Tablo 5'te VECM testi sonuçları ve ilgili test sonuçları referans alınarak hesaplanan fiyat keşif ölçütleri yer almaktadır. 
Tablo: 5

VECM testi Sonuçları ve Fiyat Keşif Ölçütleri

\begin{tabular}{|c|c|c|}
\hline \multicolumn{3}{|c|}{ Panel A: VECM ve Hata düzeltme katsayıları } \\
\hline Bağımlı Değișken & lspot & lfutures \\
\hline Hata Düzeltme Katsayısı & $-0.035967 * * *[-4.77868]$ & $-0.035154 * * *[2.58794]$ \\
\hline \multicolumn{3}{|c|}{ Panel B: Fiyat keşif Ölçütleri } \\
\hline & lspot & lfutures \\
\hline $\mathrm{CS}$ & $49.428 \%$ & $50.572 \%$ \\
\hline IS & $23.368 \%$ & $76.632 \%$ \\
\hline ILS & $8.871 \%$ & $91.129 \%$ \\
\hline
\end{tabular}

Hata düzeltme katsayısının 0 ile -1 arasında yer alması ve istatistiki olarak anlamlı olması beklenmektedir. Kurulan denklemin istenilen nitelikleri taşıdı̆̆ görülmektedir. Hata düzeltme katsayıları ve varyans kovaryans matrisi dikkate alınarak fiyat keşif ölçütleri hesaplanmıştır. CS oranı değişkenlerin sadece hata düzeltme katsayılarını referans alarak hesaplanmaktadır. CS oranına göre, vadeli piyasalar spot piyasalara göre fiyat keşif özelliğine sahiptir. Bununla birlikte, piyasalar arasındaki dağglım neredeyse eşittir. IS ve ILS oranlarının sonuçları, vadeli piyasaların baskın bir şekilde fiyat keşif fonksiyonuna sahip olduğunu göstermektedir. Vadeli piyasaların fiyat keşif oranı IS'ye göre \%76.632, ILS'ye göre \%91.129'dur. IS, değişkenlerin hata düzeltme katsayıları yanında, birbirleri ile olan ilişkilerini ifade eden kovaryans matrisini de dikkate almaktadır. CS, hata düzeltme katsayıları ile sonuçlara odaklanırken, IS bunun yanında varyans faktörü ile incelenen süreci de dikkate almaktadır. Her iki ölçü de fiyat keşfinde farklı noktalara dikkat çekmektedir. Bununla birlikte, IS ölçütü her bir değişken tarafından üretilen bilgi miktarını ölçmek için daha uygun bir ölçüdür (De Jong, 2002: 327). Yan ve Zivot (2010) ile Putniņš (2013)'in belirttiği üzere CS ve IS farklı perspektifler sunmakla birlikte farklı gürültü faktörlerinden etkilenmektedir. ILS ölçütü, CS ve IS'nın maruz kaldığı gürültü faktörünü elimine etmek amacıyla tasarlanmıştır. ILS sonuçlarına göre, fiyat keşfi büyük oranda vadeli piyasalarda gerçekleşmektedir. Her üç fiyat keşif ölçütü de vadeli piyasaların spot piyasalara göre fiyatları daha hızlı güncellediği ve daha fazla fiyat keşif gücüne sahip olduğunu göstermektedir.

VEC modeline dayanan Granger nedensellik/ blok dışsallık Wald testi sonuçları ise Tablo 6'te yer almaktadir:

Tablo: 6

VEC Granger Nedensellik Testi

\begin{tabular}{|l|c|}
\hline Boş Hipotez & $\chi^{2}$ Değeri \\
\hline lspot lfutures'un nedeni değildir. & $9.496^{* *}$ \\
\hline lfutures lspot'un nedeni değildir. & $613.281^{* * *}$ \\
\hline $\begin{array}{l}\text { Not: } * * *, * *, * \text { simgeleri sırastyla \%1, \%5 ve \%10 anlamlılık düzeyinde nedensellik ilişkisinin bulunmadığını ileri süren boş hipotezin reddedildiğini } \\
\text { ifade etmektedir. }\end{array}$ \\
\hline
\end{tabular}

VEC modelinden hareketle gerçekleştirilen Granger nedensellik/blok dışsallık Wald testleri sonuçlarına göre spot ve vadeli piyasalar arasında iki yönlü bir nedensellik ilişkisi bulunduğu tespit edilmiştir. Bununla birlikte $\chi^{2}$ test istatistikleri incelendiğinde; vadeli 
Güzel, F. (2021), "Vadeli ve Spot Kurlar Arasında Nedensellik ve Fiyat Keşfi:

Borsa İstanbul Üzerine Ampirik Bir Analiz”, Sosyoekonomi, 29(48), 427-442.

piyasadan spot piyasaya olan nedenselliğin, spot piyasadan vadeli piyasalara olan nedensellikten daha güçlü olduğu anlaşılmaktadır.

\section{Sonuç ve Tartışma}

Bu çalışmada 2014-2018 yıllarını kapsayan ve günlük veri frekansında spot ile vadeli döviz kurları arasındaki ilişki farklı perspektiflerden incelenmiştir. Öncelikle verilerin nitelik olarak değerlendirilmesi yerinde olacaktır. Gerek spot gerekse vadeli döviz kuru verileri günlük ortalama değer olarak nitelenebilecek referans fiyatlardır. Spot döviz kurları için TCMB gösterge döviz kurları, vadeli piyasa için BİST uzlaşma fiyatları kullanılmıştır. Dolayısıyla, elde edilen sonuçlar piyasalarda gün boyu gerçekleşen ticaretin ortalaması üzerinden hesaplanmıştır.

Çalışmada spot ve vadeli piyasa döviz kurlarına bilginin yansıma hızı incelenmiştir. Bu noktanın birçok piyasa katılımcısı için farklı açılardan önemi bulunmaktadır. Özellikle spekülasyon amaçlı işlem gerçekleştiren yatırımcılar için bir gelir fırsatı anlamına gelmektedir. Bu çalışmanın sonuçlarına göre, vadeli piyasaların fiyat keşif fonksiyonu daha fazladır ve vadeli piyasa referans alınarak spot piyasada pozisyon alınabilir. Vadeli piyasadaki pozitif hareketler için spot piyasada uzun pozisyon, negatif hareketler için ise kısa pozisyon tercih edilebilir. Düzenleyici ve denetleyici kurumlar için üzerine politika oluşturulabilecek bir olgu ve manipülasyon vb. yasadışı durumlar çerçevesinde önlem alınması gereken bir unsur anlamına gelmektedir. Genel ekonomi açısından değerlendirildiğinde, ekonominin dış ticarete bağımlılığının ve dış ticaret için döviz kuru riskinin kaçınılmaz olduğu Türkiye'nin mevcut ticaret ikliminde, kuru öngörebilmek ve kur riskinden korunmak için fiyat keşfi önemli bir gösterge niteliğine taşımaktadır.

Teorik literatürde vurgulandığı üzere düşük işlem maliyeti ve kaldıraç etkisi gibi faktörler vadeli piyasaları fiyat keşfi açısından spot piyasalara göre daha avantajlı konuma getirmektedir. Çalışma konusu olan Türkiye için USD/TRY döviz kuru spot ve vadeli piyasalarda da bu sonuç desteklenmiştir. Vadeli döviz kurları spot döviz kurlarına göre bilgiyi daha önce özümsemekte ve yansıtmaktadır. Fiyat keşif ölçütleri analizler aşamasında kullanılmıştır. Gonzalo ve Granger (1995) Bileşen Payı (CS), Hasbrouck (1995) Bilgi Payı (IS) ve Putniņš (2013) Bilgi Liderliği Payı (ILS) kullanılan fiyat keşif ölçütleridir. Her bir fiyat keşif ölçütünün farklı oranlar üretse de fiyat keşfinin vadeli döviz piyasasında daha baskın olduğu noktasında uzlaşı içerisinde bulundukları belirtilmelidir. Spot ve vadeli piyasa döviz kurları arasında nedensellik ilişkisi, çalışmada araştırılan bir başka noktadır. Piyasalar arasında çift yönlü bir nedensellik tespit edilmiştir. Bununla birlikte, vadeli piyasadan spot piyasaya olan nedenselliğin, spot piyasadan vadeli piyasalara olan nedensellikten daha güçlü olduğu raporlanmıştır. Ulusal literatür ile kıyaslandığında; Çevik ve Pekkaya (2007), Ozen vd. (2009) (kısa dönem) ve Demireli vd. (2010) nedensellik yönünün vadeli piyasalardan spot piyasalara doğru olduğunu vurgulamışlardır. Ozen vd. (2009) (uzun dönem) nedensellik yönünün spot piyasalardan vadeli piyasalara doğru olduğunu, Unlu ve Ersoy (2012) ise çift yönlü bir nedensellik bulgusunu raporlamıştır. Dolayısıyla, ulusal literatürün henüz bir uzlaşı içerisinde olmadığı görülmekle birlikte, çalışma sonuçlarının Unlu ve Ersoy (2012) 
ile uyumlu olduğu söylenebilir. Çalışmaların farklı sonuçlar raporlaması, yabancı literatür için de geçerlidir.

Sonuç olarak elde edilen bulgular toplu şekilde değerlendirildiğinde, incelenen dönem için vadeli piyasaların bilgisel açıdan daha etkin bir konumda olduğu görülmektedir. Böylece, vadeli piyasaların temel fonksiyonlardan biri olan fiyat keşif fonksiyonuna sahip olduğu söylenebilir. USD/TRY döviz birimi için vadeli piyasalar fiyatlara yönelik bilgi sağlama konusunda öncü kaynaktır.

\section{Kaynaklar}

Akıncı, A. \& G. Tuncer (2016), “Türkiye'de Sağlık Harcamaları ile Ekonomik Büyüme Arasındaki İlişki”, Sayıştay Dergisi, (102), 47-61.

Baillie, R.T. \& G.G. Booth \& Y. Tse \& T. Zabotina (2002), "Price Discovery and Common Factor Models", Journal of Financial Markets, 5(3), 309-321.

Bilgin, C. \& A. Şahbaz (2009), “Türkiye'de Büyüme ve İhracat Arasındaki Nedensellik İlişkileri”, Gaziantep Üniversitesi Sosyal Bilimler Dergisi, 8(1), 177-198.

Booth, G.G. \& J.C. Lin \& T. Matrikainen \& Y. Tse (2002), "Trading and Pricing in Upstairs and Downstairs Stock Markets", The Review of Financial Studies, 15(4), 1111-1135.

Booth, G.G. \& R.W. So \& Y. Tse (1999), "Price Discovery in the German Equity Index Derivatives Markets”, The Journal of Futures Markets, 19(6), 619-643.

Borsa İstanbul (2020), Döviz Vadeli İşlem Sözleşmeleri, <https://www.borsaistanbul.com/tr/sayfa/322/doviz-vadeli-islem-sozlesmeleri>, 09.03.2020.

Brooks, C. (2014), Introductory Econometrics for Finance, (3. Bask1), Cambridge: Cambridge University Press.

Cabrera, J. \& T. Wang \& J. Yang (2009), "Do Futures Lead Price Discovery in Electronic Foreign Exchange Markets?", The Journal of Futures Markets, 29(2), 137-156.

Cao, C. \& O. Hansch \& X. Wang (2009), “The Information Content of an Open Limit-Order Book", The Journal of Futures Markets, 29(1), 16-41.

Chambers, N.R. (1998), Türev Piyasalar, İstanbul: Avcılol Basım-Yayın.

Chen, R. \& Z.L. Zheng (2008), "Unbiased Estimation, Price Discovery, and Market Efficiency: Futures Prices and Spot Prices", Systems Engineering - Theory \& Practice, 28(8), 2-11.

Chen, Y.L. \& Y.F. Gau (2009), "Tick Sizes and Relative Rates of Price Discovery in Stock, Futures and Options Markets: Evidence from the Taiwan Stock Exchange", The Journal of Futures Markets, 29(1), 74-93.

Chen, Y.L. \& Y.F. Gau (2010), "News Announcements and Price Discovery in Foreign Exchange Spot and Futures Markets", Journal of Banking \& Finance, 34(7), 1628-1636.

Chu, Q.C. \& W.G. Hsieh \& Y. Tse (1999), "Price Discovery on the S\&P 500 Index Markets: An Analysis of Spot Index, Index Futures, and SPDRs", International Review of Financial Analysis, 8(1), 21-34.

Culp, C.L. (2010), "The Social Functions of Financial Derivatives”, içinde: R.W. Kolb \& J.A. Overdahl (eds.), Financial Derivatives: Pricing and Risk Management, New Jersey: John Wiley \& Sons, 57-71. 
Çevik, E.İ. \& M. Pekkaya (2007), "Spot ve Vadeli İşlem Fiyatlarının Varyansları Arasındaki Nedensellik Testi”, Dokuz Eylül Üniversitesi İktisadi ve İdari Bilimler Fakültesi Dergisi, 22(2), 49-66.

Damodaran, A. \& M.G. Subrahmanyam (1992), "The Effect of Derivative Securities on the Market for the Underlying Assets in the United States: A Survey", Financial Markets, Institutions and Instruments, 1(5), 1-22.

De Boyrie, M.E. \& I. Pavlova \& A.M. Parhizgari (2012), "Price Discovery in Currency Markets: Evidence from Three Emerging Markets", International Journal of Economics and Finance, 4(12), 61-75.

De Jong, F. (2002), "Measures of Contributions to Price Discovery: A Comparison”, Journal of Financial Markets, 5(3), 323-327.

Demirci, N.S. (2017), "İmalat Sanayi Sektöründe Üretim ve Banka Kredileri İlişkisi: Türkiye İçin Eşbütünleşme ve Nedensellik İlişkisi”, Dokuz Eylül Üniversitesi Sosyal Bilimler Enstitüsü Dergisi, 19(1), 35-61.

Demireli, E. \& E. Gülmez \& C. Akkaya (2010), "Vadeli ve Spot Kurlar Arasındaki Nedensellik İlişkisi: İzmir Vadeli İşlem ve Opsiyon Borsası Üzerine Bir Uygulama”, Dumlupınar Üniversitesi Sosyal Bilimler Dergisi, (27), 325-334.

Dickey, D.A. \& W.A. Fuller (1981), "Likelihood Ratio Statistics for Autoregressive Time Series with a Unit Root", Econometrica, 49(4), 1057-1072.

Enders, W. (2014), Applied Econometric Time Series, (4. Bask1), New Jersey: Wiley.

Engle, R.F. \& C.W.J. Granger (1987), “Co-Integration and Error Correction: Representation, Estimation, and Testing", Econometrica, 55(2), 251-276.

Erdoğan, O. \& M. Kayacan (1998), "Finansal Türevlere Ne Zaman Başlanmalı? İstanbul Menkul Kıymetler Borsası Örneği”, IMKB Dergisi, 2(5), 23-45.

Ersoy, E. (2011), "Spot ve Vadeli İşlem Piyasaları Arasındaki Fiyat ve Volatilite İlişkisi: İMKBVOB Örneği”, Erciyes Üniversitesi Sosyal Bilimler Enstitüsü, Doktora Tezi, Kayseri.

Gonzalo, J. \& C. Granger (1995), "Estimation of Common Long-Memory Components in Cointegrated Systems", Journal of Business \& Economic Statistics, 13(1), 27-35.

Granger, C.J.G. \& P. Newbold (1974), "Spurious Regression in Econometrics”, Journal of Econometrics, 2(2), 111-120.

Granger, C.W.J. (1969), "Investigating Causal Relations by Econometric Models and Cross-spectral Methods", Econometrica, 37(3), 424-438.

Gujarati, D.N. (2004), Basic Econometrics, (4. Bask1), Londra: McGraw Hill.

Guru, A. (2010), "Interplay Between Exchange Traded Currency Futures Markets, Spot Markets and Forward Markets: A Study on India", Indian Economic Review, New Series, 45(1), 111130.

Harris, F.H. de B. \& T.H. McInish \& R.A. Wood (2002), "Security Price Adjustment Across Exchanges: An Investigation of Common Factor Components for Dow Stocks", Journal of Financial Markets, 5(3), 277-308.

Hasbrouck, J. (1995), “One Security, Many Markets: Determining the Contributions to Price Discovery”, The Journal of Finance, 50(4), 1175-1199.

Inani, S.K. (2018), "Price Discovery and Efficiency of Indian Agricultural Commodity Futures Market: An Empirical Investigation", Journal of Quantitative Economics, 16, 129-154. 
Johansen, S. \& K. Juselius (1990), "Maximum Likelihood Estimation and Inference on Cointegration-With Applications to the Demand for Money", Oxford Bulletin of Economics and Statistics, 52(2), 169-210.

Johansen, S. (1988), "Statistical Analysis of Cointegration Vectors", Journal of Economic Dynamics and Control, 12(2-3), 231-254.

Johansen, S. (1991), "Estimation and Hypothesis Testing of Cointegration Vectors in Gaussian Vector Autoregressive Models", Econometrica, 59(6), 1551-1580.

Johansen, S. (1995), Likelihood-Based Inference in Cointegrated Vector Autoregressive Models, New York: Oxford University Press.

Kayalıdere, K. \& H. Aracı \& H. Aktaş (2012), “Türev ve Spot Piyasalar Arasındaki Etkileşim: VOB Üzerine Bir İnceleme”, Muhasebe ve Finansman Dergisi, (56), 137-154.

Korczak, P. \& K. Phylaktis (2010), "Related Securities and Price Discovery: Evidence from NYSElisted Non-U.S. Stocks", Journal of Empirical Finance, 17(4), 566-584.

Kumar, S. (2018), "Price Discovery in Emerging Currency Markets", Research in International Business and Finance, 46, 528-536.

Kwiatkowski, D. \& P.C.B. Phillips \& P. Schmidt \& Y. Shin (1992), "Testing the Null Hypothesis of Stationarity Against the Alternative of a Unit Root", Journal of Econometrics, 54(1-3), 159-178.

MacKinnon, J.G. \& A.A. Haug \& L. Michelis (1999), "Numerical Distribution Functions of Likelihood Ratio Tests for Cointegration", Journal of Applied Econometrics, 14(5), 563 577.

MacKinnon, J.G. (1996), "Numerical Distribution Functions For Unit Root and Cointegration Tests", Journal of Applied Econometrics, 40, 601-618.

Narayan, P.K. \& R. Smyth (2006), "What Determines Migration Flows from Low-Income to HighIncome Countries? An Empirical Investigation of Fiji-U.S. Migration 1972-2001”, Contemporary Economic Policy, 24(2), 332-342.

Ozen, E. \& T. Bozdogan \& M. Zugul (2009), "The Relationship of Causality Between the Price of Futures Transactions Underlying Stock Exchange and Price of Cash Market: The Case of Turkey", Middle Eastern Finance and Economics, (4), 28-37.

Phillips, P.C.B. \& P. Perron (1988), "Testing for a Unit Root in Time Series Regression”, Biometrika, 75(2), 335-346.

Prabha, A. \& K. Savard \& H. Wickramarachi (2014), "Deriving The Economic Impact of Derivatives: Growth Through Risk Management", Milken Institute, $<$ http://assets1b.milkeninstitute.org/assets/Publication/ResearchReport/PDF/DerivativesReport.pdf>, 11.03.2020.

Putniņš, T.J. (2013), “What do Price Discovery Metrics Really Measure?”, Journal of Empirical Finance, 23, 68-83.

Sakarya, Ş. \& H.T. Akkuş (2018), "BİST100 ve BİST Sektör Endeksleri ile VIX Endeksi Arasındaki İlişkinin Analizi”, Ballkesir Üniversitesi Sosyal Bilimler Enstitüsü Dergisi, 21(40), 351373.

Sakthivel, P. \& K.R. Chittedi \& D. Sakyi (2017), "Price Discovery and Volatility Transmission in Currency Spot and Futures Markets in India: An Empirical Analysis", Global Business Review, 20(4), 1-15. 
Sehgal, S. \& W. Ahmad \& F. Deisting (2015), “An Investigation of Price Discovery and Volatility Spillovers in India's Foreign Exchange Market”, Journal of Economic Studies, 42(2), 261-284.

Sevüktekin, M. \& M. Çınar (2017), Ekonometrik Zaman Serileri Analizi: EViews Uygulamalı (5. Baskl), Bursa: Dora.

So, R.W. \& Y. Tse (2004), "Price Discovery in the Hnag Seng Index Markets: Index, Futures, and theTracker Fund", The Journal of Futures Markets, 24(9), 887-907.

Stock, J.H. \& M.W. Watson (2015), Introduction to Econometrics (3. Baskl), Londra: Pearson.

Tarı, R. (2011), Ekonometri (7. Baskl), Kocaeli: Umuttepe Yayınları.

Tse, Y. \& J.K.W. Fung \& J. Xiang (2006), "Price Discovery in the Foreign Exchange Futures Market", The Journal of Futures Markets, 26(11), 1131-1143.

Türkiye İstatistik Kurumu (2020), Dış Ticaret İstatistikleri, <http://www.tuik.gov.tr/PreTablo.do?alt_id=1046>, 07.03.2020.

Unlu, U. \& E. Ersoy (2012), "The Causal Relationship Between Foreign Currency Futures and Spot Market: Evidence from Turkey", Investment Management and Financial Innovations, 9(2), 208-212.

Yan, B. \& E. Zivot (2010), “A Structural Analysis of Price Discovery Measures”, Journal of Financial Markets, 13(1), 1-19. 